\title{
Comparative study of quality of life and coping strategies in family of patients with major depression and bipolar disorder and in families without mental patient
}

\author{
Research Article
}

\author{
Farahnaz Esmailvandi $^{1}$, Masoud Bahreini ${ }^{2 *}$, Kamran Mirzae ${ }^{3}$, Maryam Ravanipoure $^{4}$ \\ 1. MSc Student of Psychiatric Nursing, Faculty of Nursing and Midwifery, \\ Bushehr University of Medical Sciences, Bushehr, Iran \\ 2. Faculty Member of Department of Nursing, Faculty of Nursing and Midwifery, \\ Bushehr University of Medical Sciences, Bushehr, Iran \\ 3. Faculty Member of social medicine, Bushehr University of Medical Sciences, Bushehr, Iran \\ 4. Faculty Member of Department of Nursing, Faculty of Nursing and Midwifery, \\ Bushehr University of Medical Sciences, Bushehr, Iran
}

\begin{abstract}
Introduction: Evidence-based nursing and self-efficacy are significant factors behind quality care delivery in critical care units. Aim: This study aimed to assess the effects of an evidence-based nursing training workshop on critical care nurses' self-efficacy. Methods: This two-group pretest-posttest quasi-experimental study was undertaken in 2016 in two large-scale hospitals in Tehran, Iran. The participating nurses from one hospital were purposefully allocated to the intervention group and the other hospital's participants comprised the control group. A convenience sample of 45 nurses was selected from each hospital. For nurses in the intervention group, an evidence-based nursing training workshop was held in four two-hour sessions on two successive days, while the nurses in the control group received no specific evidence-based nursing training. Findings: After the intervention, these values increased to $51.1 \pm 2.49$ and $61.6 \pm 2.05$, respectively. The increase in the intervention group was statistically significant $(\mathrm{P}=0.001)$, while the increase in the control group was insignificant $(\mathrm{P}=0.06)$. Thus, the posttest mean score of self-efficacy in the intervention group was significantly greater than the control group. Conclusion: Evidence-based nursing training significantly improves the nurses' self-efficacy. Therefore, healthcare policy-makers and authorities are recommended to provide nurses with in-service and evidence-based nursing training programs.
\end{abstract}

Keywords: Quality of life, coping strategies, major depression, bipolar mood disorder.

\section{Introduction}

Nowadays, the problems of mental health and the prevalence of mental disorders as a global problem are growing and worrying(1, 2). Mental disorders are important health problems for undesirable outcomes such as suicide, divorce and severe reduction of individual and social performance; they impose high pressure on health care services in today's societies (3, 4). Statistics show that there are about 450 million people diagnosed with mental disease in the world (3, 5). Also, according to World Health Organization statistics, more than 25 percent of the world's population are affected by a mental disorder. This indicates that a family of all four families in the world is involved in the care of mental patients $(5,6)$.

Bipolar disorder and major depression are common psychiatric disorders that lead to hospitalization in a hospital (7). The incidence of each of these disorders is $6 \%$ and $5.2-17.1 \%$, respectively(4, $8)$. Bipolar disorder is one of the mood disorders that

\footnotetext{
*Corresponding Author:

Masoud Bahreini,

Faculty Member of Department of Nursing,

Faculty of Nursing and Midwifery,

Bushehr University of Medical Sciences,

Bushehr, Iran

Email id: msdbahreini@yahoo.com
}

are classified as one of the most disabling psychological disorders (9). It is a recurring periodical disease of depression and mania or hypomania (10). The mood of the individual with bipolar disorder is abnormally high and irritable; increase in self-confidence, reduction of the need for sleep, verbosity and the thought leaping are some of its symptoms (11). Dipolar disease causes disruption of work, education, marital affairs and social communication $(9,12)$. Major depression is one of the most common psychiatric disorders. Some of its signs are sadness, feeling of forgiveness and sin, loss of interest and pleasure from everyday activities. In the lower social-economic classes, it is seen (8).

Mental diseases affect not only the patients but also their family (13). With the recent advances in biological therapy and the deinstitutionalization movement, the need for long-term admissions of psychiatric patients and the role of family in the treatment process have increased. Also, by changing the service delivery system, families play a key role in care, support and long-term treatment (13-16).

At the same time, the burden of care, as a major challenge, affects the lives of the family of mental patients (17) and changes the pattern of performance, roles, and tasks. The results of some researches have shown that the signs of anxiety, depression and psychosis in family members of mental patients are increasing $(5,18,19)$. Also, these families may 
experience problems such as disorder in family relations, limited community presence, lack of time for personal pleasure, lack of motivation and economic difficulties $(20,21)$. Researchers believe that the families in which the patients are cared, the caregivers' level of care affects the quality of life of caregivers (10).

Quality of life is defined as the perception of a person of his place in life, according to the value and cultural system of society, goals, criteria and factors of the individual $(22,23)$. Quality of life is a broad concept that includes the health of performance, the socioeconomic status, and the psychological, and spiritual dimensions of an individual (23, 24). Nowadays, quality of life associated with health in chronic patients is used as an indicator for the study of the effects of disease, treatment and care (22).

Individual's reaction against stress and coping strategies that they choice to face may also predispose people to disease, especially mental disorders. Coping strategies are one of the broadest subjects in contemporary psychology. Some researchers identify coping strategies as one of the most important psychosocial-social factors that determine the relationship between stress and disease (23, 25). Folkman and Lazarus recognize coping as a complex and dynamic process that varies from person to person depending on the appraisal of stressful situation. Researchers also believe that coping is a behavioral and mental response that is classified into both the emotionand problem-oriented ways $(2,6,23)$.

Emotional response helps to manage negative feelings in relation to the stressful situation and reduces the distress caused by it. It also maintains emotional balance through the controlling of the emotions resulting from the tense position. The problem-oriented approach refers to individual efforts and constructive actions to change the underlying basis of stress seeking to find a way to reduce the threatening state $(6,26)$. Lazarus and Folkman argue that people use both strategies to deal with problems, but the problem-oriented coping seems to be the most adaptive style of coping and is trying to eliminate or change the source of stress and tension (2, 27). Healthy coping strategies include positive thinking, social support (family, friends and mental health services), information about disease, spiritual beliefs and the unhealthy coping strategies include negative thinking, behaviors such as leaving the family member of the patient, addiction (such as drug use), and avoidance behaviors $(6,28)$. Coping strategies play an important role in adapting to the stressful situation of life (4). By investigating the relationship between coping styles and mental health of 140 military personnel of the Islamic Republic of Iran in Tehran, Khedri et al. (2014) concluded that recognizing and using emotion-focused and problem-based coping strategies has a significant effect on the mental health of soldiers. (2) In another study by Sharif Ghaziani et al. (2013) to determine the factors related to the quality of life of families with mental patients, 242 families of psychiatric patients in Rasht were studied. The results of this study showed that the quality of life of women who care for mental patients is weaker than men. These results indicate the need to pay more attention to care-and-therapeutic and social support that enhances the well-being and quality of life in this group of caregivers (3). Also, in a study conducted by Tamizi et al. (2007) entitled "Investigating the relationship between quality of life and coping strategies" on 90 schizophrenic patients referred to psychiatric clinics of Tehran teaching hospital, the results showed that there is a significant relationship between quality of life and coping strategies. The researcher concludes in this study that coping strategies to deal with stress can affect the quality of life of individuals, and the recognition of the relationship between these strategies and the quality of life of individuals is very important (4).

Therefore, since the family of psychiatric patients undergoes a lot of stresses, it should take a long time to adapt to these conditions. In the meantime, the coping strategies used by family members of mental patients as protectors contribute considerably to adaptation and acceptance of the problem $(6,16,29)$. Researches have shown that in families where relationships between members and family-based interactions are based on proximity and understanding, and the mental health of individuals is favorable, they are immune to life pressures and are better suited to problems (30). Accordingly, due to the high prevalence of psychiatric disorders, the role and place of the family in the societal structure, and also considering the importance of concepts of quality of life and coping strategies as important criteria for mental health, this study aimed to compare the quality of life and coping strategies of Families of patients with major depression and bipolar disorder with the families without any psychosocial patient in Bushehr were designed and implemented.

\section{Methodology}

The present research was a cross-sectional study. The research population consisted of all families of patients with major depression disorder and bipolar disorder referring to psychiatric hospital and private psychiatric center as well as the families without mental patients referring to Bushehr health centers. The method was random sampling with allocating quota. According to the number of patients registered in different parts of the research environment (psychiatric hospital, private psychiatric centers and health centers of Bushehr), the share of samples of each environment was determined and then randomly the samples were selected from the environment.

Regarding the study of Nasimikhah (31)and taking into account the quality of life score in the family of patients with bipolar disorder, major depression and the individuals without psychiatric patients were 12.81 $\pm 9.08,78.06 \pm 5.82$ and $114.34 \pm 7.43$, assuming $\alpha=0.05$ and $\beta=0.01$; using the formula

$$
\mathrm{N}=2\left(\mathrm{z}_{1-\alpha / 2}{ }^{2}+\mathrm{z}_{1-\beta}{ }^{2}\right) \mathrm{s}^{2} /\left(\mu_{1}-\mu_{2}\right)^{2}
$$

Sample size was estimated to be 30 people. However, the researchers decided to increase the number of samples to 40, considering the probability of not responding exactly to the questionnaire and its failure to be completed, with $30 \%$ of the non-response.

Also, according to the study of Ghazanfari et al. 
(32) and the relationship between emotional coping strategies and depression $(\mathrm{r}=0.429)$, general mental health $(\mathrm{r}=0.575)$, assuming $\alpha=0.05$ and $\beta=0.1$, using Formula

$$
\mathrm{N}=\left(\mathrm{z}_{1-\alpha / 2}{ }^{2}+\mathrm{z}_{1-\beta}{ }^{2}\right)^{2} / \omega^{2} \quad \omega=1 / 2 \log (1+\mathrm{r} / 1-\mathrm{r})
$$

The sample size was estimated to be 17 people in each group; according to the need for a larger sample size to assess the quality of life in the family of patients with bipolar disorder, major depression and the individuals without mental disease, the sample size was generally estimated at least 40 people in the family of patients with bipolar disorder, major depression and the families without mental disease. One of the members of the psychiatric family who had the following criteria for participation in study was selected as the sample: being the main caregiver of mental patient, being the parent of mental patient, living with of mental patient, at least 6 months of being the caregiver of mental patient and having written consent for participation in study. Also, one of the members of the family without mental patient was included in the study with the following criteria: being the mother or the father of the family without child with a psychiatric disease, the parent has no history of mental disease, without history of chronic disease and having written consent for participation in study. The exclusion criterion was the reluctance of families to participate in research.

Data collection tools were Lazarus and Folkman coping strategies questionnaire and quality of life questionnaire SF 36. The first part of the questionnaire included demographic information (age, gender, marital status, level of education, place of residence), completed by families (father or mother). The second part was the quality of life questionnaire. The 36-item questionnaire was designed by Warwhiron in 1992 in the United States. The purpose of this scale is to assess the health status of the physical and mental dimensions. This questionnaire is a valid questionnaire widely used to assess quality of life (23). The quality of life questionnaire consists of 36 questions of eight scales, each scale consisting of 2 to 10 items. The subscales of this questionnaire are as follows: 1-Physical function 2Role disorder due to physical health 3-Role disorder due to emotional health 4-Energy / Fatigue 5-Emotional well -being 6 -Social function 7-Pain 8-General health. The questionnaire consisted of 36 questions that included physical function (10 questions), role disorder due to physical health (4 questions), role disorder for emotional health (3 questions), energy / fatigue (4 questions), emotional well-being (5 Questions), social function (2 questions), pain ( 2 questions) and general health (4 questions). The scale of the physical function part of this questionnaire is a Likert three-option scale that includes I have a problem (1), I have a few problems (2), I have no problem at all (3), and the scales of role disorder for physical health and role disorder for emotional health are two-option scales including Yes (1) and No (2); the scales of energy / fatigue and emotional well-being are Likert six-optional ones, which include all the time (1), most often (2), a large part of the time (3), sometimes (4), A small part of the time (5), at no time (6); the social function scale is Likert 5-optional, the first one of which consists of no (1), partially (2), relatively moderate (3), some (4) Extremely high (5) and question 2 consists of all the time (1), most often (2), sometimes (3), a small part of the time (4), no time (5); the scale of pain: the question 1 of this scale is 6-optional, including no (1), very mild (2), mild (3), moderate (4), severe (5), very severe (6), and question 2 is a Likert 5-option scale, which is unobstructed (1) ), Slightly (2), on average (3), almost partially (4), extremely high (5); the general health scale is a Likert 5-optional one, the first question is excellent (1), very good (2), good (3), moderate (4) and weak (5) and the rest of the questions are completely correct (1), more correct (2), I do not know (3), more false (4), completely false (5). Reliability and validity of the questionnaire SF-36 have been studied in Iran. The reliability of the questionnaire SF-36 in Iran in all areas ranged from 0.65. To 0.90 and the correlation of each question with the whole test was also between 0.58 up to 0.95 (33). In this questionnaire for quality of life and its subscales, the lowest score is zero (worst condition) and the highest score (best condition) is 100. Completion of the questionnaire took 10 minutes.

The third part was the Lazarus and Folkman coping strategies questionnaire. This is a 66-item questionnaire developed by Lazarus and Folkman based on a cognitive-phenomenological theory of tension, estimation and coping, and measures the thoughts and deeds that the individual uses to deal with everyday stresses. The Lazarus coping strategies questionnaire has 8 sub-tests: 1- Direct Coping (6 questions) 2Distancing (6 questions) 3- Self-control (7 questions) 4social support (6 questions) 5- acceptance of responsibility (4 questions) 6-Evasion-Avoidance (8 questions) 7-Planned problem solving (6 questions) 8Positive reappraisal ( 7 questions). These 8 patterns are divided into two categories of problem-oriented methods (social support, planned problem solving, accepting responsibility, and positive reappraisal) and emotion-oriented methods (direct copying, distancing, self-control, and escape-avoidance). It is scaled on the basis of a Likert four-option scale (not at all, sometimes, usually, much), based on a grading scale of zero to three. Person's score per scale is obtained from his total score of questions specific to that scale. Ghadamgahi \& Dojkam used the Cronbach's alpha and reported the coefficient of internal consistency to be from 0.61 to $0.79(34)$, with a re-test validity of 0.59 0.83 for a four-week interval(35). completion of the questionnaire took 20 minutes.

In order to conduct the research, the researcher identified the criteria for participating in the study by referring to the psychiatric hospital and the private psychiatric clinics of the family of patients (major depression and bipolar disorder). After identifying the main caregivers of patients with mood disorders, the questionnaires were provided to the samples. If the main caregiver of patients with mood disorders were absent in these centers, an appointment would be made to fill out questionnaires with the caregiver at the hospital. 
Before completing the questionnaires, the necessary information about the study objectives was presented to the samples and the informed consent form was completed. In this section, it was explained to the samples that the participation in the research was optional, and due to the confidentiality of the information of individuals, their family names were not included in the questionnaire. The informed consent form and the questionnaire for those carers who did not have the ability to read and write were completed by the researcher. During the entire four months, the data was collected from the samples of this study.

Data were analyzed using SPSS software version 22 and chi-square, Kruskal-Wallis, ANCOVA and Bonferroni, Mann-Whitney and Spearman correlation tests. The significance level was considered to be $(\mathrm{p}<0.05)$.

\section{Findings}

[Table 1] shows the frequency of demographic variables of participants in the study by groups. 67 people $(55.8 \%)$ of samples were male and 53 people $(44.1 \%)$ of them were female. Most of the units under study were married, living in the city with a bachelor's degree and above. Statistical analysis showed that there was no significant difference in terms of marital status, place of residence and educational level among the groups, but the statistical analysis indicated a significant difference between the families of participants in terms of gender.

Table 1: Comparison of frequency of demographic variables of participants in the study by groups

\begin{tabular}{|c|c|c|c|c|c|c|}
\hline & & & $\begin{array}{l}\text { Number } \\
\text { (percent) }\end{array}$ & & $\begin{array}{l}\text { Statistical } \\
\text { index of } x^{2}\end{array}$ & p-value \\
\hline $\begin{array}{l}\text { Demographic } \\
\text { characteristics }\end{array}$ & & $\begin{array}{l}\text { Without mental } \\
\text { patient } N(\%)\end{array}$ & $\begin{array}{c}\text { Major depression } \\
\mathrm{N}(\%)\end{array}$ & $\begin{array}{l}\text { Bipolar } \\
\mathrm{N}(\%)\end{array}$ & & \\
\hline \multirow[t]{2}{*}{ Gender } & Male & $15(37.5)$ & $24(60)$ & $28(70)$ & 8.989 & 0.011 \\
\hline & Female & $25(62.5)$ & $16(40)$ & $12(30)$ & & \\
\hline \multirow[t]{3}{*}{ Marital status } & Married & $39(97.5)$ & $39(97.5)$ & $37(92.5)$ & & \\
\hline & Divorced & $0(0)$ & $1(2.5)$ & $0(0)$ & 5.970 & 0.234 \\
\hline & Spouse's death & $1(2.5)$ & $0(0)$ & $3(7.5)$ & & \\
\hline \multirow{2}{*}{$\begin{array}{l}\text { Place of } \\
\text { residence }\end{array}$} & City & $37(92.5)$ & $37(92.5)$ & $35(87.5)$ & 0.801 & 0.670 \\
\hline & Village & $3(7.5)$ & $3(7.5)$ & $5(12.5)$ & & \\
\hline \multirow{4}{*}{$\begin{array}{l}\text { Educational } \\
\text { level }\end{array}$} & Illiterate & $8(20)$ & $4(10)$ & $7(17.5)$ & & \\
\hline & Under diploma & $8(20)$ & $10(25)$ & $10(25)$ & 4.509 & 0.680 \\
\hline & Diploma & $8(20)$ & $13(32.5)$ & $13(32.5)$ & & \\
\hline & Bachelor and over & $16(40)$ & $13(32.5)$ & $10(25)$ & & \\
\hline
\end{tabular}

[Table 2] shows the lack of difference between the three groups in terms of indices of physical function, role disorder due to physical health, role disorder due to emotional health, emotional well-being, social function, pain, general health, physical health, and energy / fatigue components.

Table 2: Comparison of the mean of quality of life and its areas in the family of patients with bipolar disorder, major depression disorder and family of patients without mental disease

\begin{tabular}{|c|c|c|c|}
\hline Quality of life variable & Family & Mean and standard deviation & p-value* \\
\hline \multirow{3}{*}{ Physical function } & Without mental patient & $77.32 \pm 13.00$ & \multirow{3}{*}{0.752} \\
\hline & Bipolar & $73.93 \pm 24.25$ & \\
\hline & Major depression & $73.43 \pm 21.54$ & \\
\hline \multirow{3}{*}{ Role disorder due to physical health } & Without mental patient & $87.12 \pm 29.51$ & \multirow{3}{*}{0.051} \\
\hline & Bipolar & $60.00 \pm 36.16$ & \\
\hline & Major depression & $58.12 \pm 12.58$ & \\
\hline \multirow{3}{*}{ Role disorder due to emotional health } & Without mental patient & $49.56 \pm 36.17$ & \multirow{3}{*}{0.182} \\
\hline & Bipolar & $43.33 \pm 71.97$ & \\
\hline & Major depression & $35.36 \pm 36.12$ & \\
\hline \multirow{3}{*}{ Energy-fatigue } & Without mental patient & $87.64 \pm 18.41$ & \multirow{3}{*}{0.062} \\
\hline & Bipolar & $58.37 \pm 20.58$ & \\
\hline & Major depression & $55.12 \pm 20.17$ & \\
\hline \multirow{3}{*}{ Emotion well-being } & Without mental patient & $69.60 \pm 18.62$ & \multirow{3}{*}{0.051} \\
\hline & Bipolar & $61.50 \pm 20.18$ & \\
\hline & Major depression & $85.60 \pm 18.83$ & \\
\hline \multirow{3}{*}{ Social function } & Without mental patient & $68.43 \pm 23.16$ & \multirow{3}{*}{0.259} \\
\hline & Bipolar & $63.75 \pm 24.15$ & \\
\hline & Major depression & $59.37 \pm 25.59$ & \\
\hline
\end{tabular}


Farahnaz Esmailvandi et.al., Quality of life and coping strategies in family

\begin{tabular}{|c|c|c|c|}
\hline Quality of life variable & Family & Mean and standard deviation & p-value* \\
\hline \multirow{3}{*}{ Pain } & Without mental patient & $78.00 \pm 19.53$ & \multirow{3}{*}{0.209} \\
\hline & Bipolar & $73.93 \pm 25.12$ & \\
\hline & Major depression & $69.43 \pm 27.11$ & \\
\hline \multirow{3}{*}{ General health } & Without mental patient & $64.50 \pm 19.00$ & \multirow{3}{*}{0.450} \\
\hline & Bipolar & $56.37 \pm 20.53$ & \\
\hline & Major depression & $59.50 \pm 22.97$ & \\
\hline \multirow{3}{*}{ Physical health } & Without mental patient & $74.48 \pm 15.70$ & \multirow{3}{*}{0.104} \\
\hline & Bipolar & $66.06 \pm 21.05$ & \\
\hline & Major depression & $65.12 \pm 22.64$ & \\
\hline \multirow{3}{*}{ Mental health } & Without mental patient & $63.12 \pm 19.37$ & \multirow{3}{*}{0.049} \\
\hline & Bipolar & $56.83 \pm 20.25$ & \\
\hline & Major depression & $52.12 \pm 20.95$ & \\
\hline \multirow{3}{*}{ Overall quality of life } & Without mental patient & $68.80 \pm 19.97$ & \multirow{3}{*}{0.045} \\
\hline & Bipolar & $61.45 \pm 19.16$ & \\
\hline & Major depression & $58.62 \pm 20.95$ & \\
\hline
\end{tabular}

ANCOVA*

Analysis of covariance test (by adjusting the effects of differences in terms of gender and age of participants in the study) revealed a significant difference between the three groups respecting overall quality of life and mental health components. Mental health as well as quality of life in the family of patients with major depression disorder were lower than that without mental patient, but there was not observed any difference between the families of the two other groups [Table 3].

The analysis of the statistical test of covariance (by adjusting the effects of differences of the gender and the age of the participants in the study) showed no significant difference between the three groups of families in terms of direct coping components, distancing, self-control, social support, acceptance of responsibility, planned problem solving, positive reappraisal, and problem-oriented coping. Also, the results of the statistical test of covariance indicated a significant difference between the three groups in terms of escape and avoidance index and also the emotion-oriented coping strategies. Thus, Bonferroni follow-up test showed that the two families of patients with major depression disorder and bipolar disorder did not differ from each other. However, the family of the individuals without mental disease used this strategy less than the families of the other two groups [Table 3].

Table 3: Comparison of the mean of coping strategies in the family of patients with bipolar disorder, major depression disorder and the family without mental patient

\begin{tabular}{|c|c|c|c|}
\hline Coping strategies variable & Family & Mean and standard deviation & p-value" \\
\hline \multirow{3}{*}{ Direct coping } & Without mental patient & $7.30 \pm 2.61$ & \multirow{3}{*}{0.298} \\
\hline & Bipolar & $8.52 \pm 3.19$ & \\
\hline & Major depression & $8.20 \pm 3.68$ & \\
\hline \multirow{3}{*}{ Distancing } & Without mental patient & $8.07 \pm 3.16$ & \multirow{3}{*}{0.074} \\
\hline & Bipolar & $9.50 \pm 2.96$ & \\
\hline & Major depression & $9.30 \pm 3.22$ & \\
\hline \multirow{3}{*}{ Self-control } & Without mental patient & $10.47 \pm 3.16$ & \multirow{3}{*}{0.088} \\
\hline & Bipolar & $11.77 \pm 3.89$ & \\
\hline & Major depression & $11.55 \pm 3.99$ & \\
\hline \multirow{3}{*}{ Escape-avoidance } & Without mental patient & $6.82 \pm 2.80$ & \multirow{3}{*}{0.001} \\
\hline & Bipolar & $10.20 \pm 4.71$ & \\
\hline & Major depression & $10.50 \pm 4.35$ & \\
\hline \multirow{3}{*}{ Social support } & Without mental patient & $10.70 \pm 3.13$ & \multirow{3}{*}{0.785} \\
\hline & Bipolar & $10.92 \pm 3.74$ & \\
\hline & Major depression & $10.70 \pm 3.84$ & \\
\hline \multirow{3}{*}{ Acceptance of responsibility } & Without mental patient & $6.90 \pm 2.23$ & \multirow{3}{*}{0.385} \\
\hline & Bipolar & $6.30 \pm 2.73$ & \\
\hline & Major depression & $6.00 \pm 2.27$ & \\
\hline \multirow{3}{*}{ Planned problem-solving } & Without mental patient & $9.42 \pm 2.78$ & \multirow{3}{*}{0.142} \\
\hline & Bipolar & $10.45 \pm 3.38$ & \\
\hline & Major depression & $10.37 \pm 3.54$ & \\
\hline \multirow{3}{*}{ Positive reappraisal } & Without mental patient & $12.15 \pm 3.80$ & \multirow{3}{*}{0.585} \\
\hline & Bipolar & $11.85 \pm 3.64$ & \\
\hline & Major depression & $11.45 \pm 4.00$ & \\
\hline
\end{tabular}




\begin{tabular}{|l|l|c|l|}
\hline Coping strategies variable & Family & Mean and standard deviation & p-value* \\
\hline \multirow{3}{*}{ Emotion-oriented coping } & Without mental patient & $32.67 \pm 8.17$ & 0.001 \\
\cline { 2 - 4 } & Bipolar & $40.00 \pm 10.46$ \\
\cline { 2 - 4 } & Major depression & $39.55 \pm 12.03$ & 0.543 \\
\hline \multirow{3}{*}{ Problem-oriented coping } & Without mental patient & $39.17 \pm 9.42$ & $39.52 \pm 11.02$ \\
\cline { 2 - 4 } & Bipolar & $38.52 \pm 11.38$ \\
\cline { 2 - 4 } & Major depression & \\
\hline
\end{tabular}

*ANCOVA

Spearman statistical analysis revealed the lack of a significant linear relationship between quality of life and the components of problem- and emotion-oriented strategies in the family of patients with major depression. Also, there was not a significant linear relationship between the quality of life and the problem- and emotion-oriented indices in the family of dipolar patients.

In the family without mental patient, there was no significant linear relationship between quality of life and the emotion-oriented component, but between quality of life and the problem-oriented strategy, there was a direct and significant linear relationship; with increasing or decreasing quality of life, the problem-oriented coping strategy increased or decreased [Table 4].

Table 4: Correlation between quality of life and coping strategies in participants in the study

\begin{tabular}{|l|l|c|c|}
\hline Group & Coping strategies & Rho & p-value* \\
\hline \multirow{2}{*}{ Major depression } & Problem-oriented & 0.106 & 0.516 \\
\cline { 2 - 4 } & Emotion-oriented & -0.054 & 0.741 \\
\hline \multirow{2}{*}{ Bipolar } & Problem-oriented & 0.140 & 0.388 \\
\cline { 2 - 4 } & Emotion-oriented & 0.100 & 0.537 \\
\hline \multirow{2}{*}{ Without mental patient } & Problem-oriented & 0.328 & 0.039 \\
\cline { 2 - 4 } & Emotion-oriented & -0.075 & 0.646 \\
\hline
\end{tabular}

*Spearman Correlation

\section{Discussion and conclusion}

The results of the comparison of the mean scores of quality of life in the families of patients with major depression disorder, dipolar and the families without psychiatric patients showed that the overall mean of quality of life and most of its areas in the families of individuals without psychiatric patients was higher than that seen in the family of patients with major depression and bipolar disorder. These results indicated that the difference between the overall mean of quality of life and the mental health area was significant, so that the overall mean of quality of life and the mental health of the quality of life in the family of patients with major depression were lower than those without mental patient; there was no difference between the families of other two groups, the family of bipolar patients and the family of patients without mental disease.

The results of our study on the quality of life of the family of patients with mental disease were consistent with the studies of Nasimikhah et al (2014), Sharif Ghaziani et al (1392), Lee et al (2007) and Baer et al. (2012) and Wong et al. (2012). Studies have shown that life stresses, including the presence of a person with mental disease, can affect other family members, especially parents. Most parents are very worried about their patient's future, relapse, severity of disease and the care for their patients. They spend a lot of time for taking care of and managing their child's mental health problems and coping with their behavioral difficulties. Carers of patients with mental disease bear great burden and responsibility; this may have a negative impact on them, which is why their quality of life and their mental health are lower than other people in society. In comparison, many families without mental patient do not experience these issues and have more time to handle their affairs ${ }^{(3,17,19,21,31)}$.

The comparison of the mean scores of other areas of quality of life among the three groups of families showed that these indices are almost the same in all three groups of families. These results indicate that the quality of life among the families under study is affected by other factors, regardless of whether there is a mental patient in these families; it should be considered in further research.

The results of this study showed that there was no significant difference between the majority of coping strategies components except for components of escape and avoidance in the family of patients with major depression disorder and bipolar disorder and the family without mental patient. This study revealed the difference between the three groups of the family in terms of emotion-oriented coping strategies and the index of escape and avoidance, so that the two families of patients with major depression disorder and bipolar disorder did not differ, but the family of the individuals without mental patient used this strategy less than that of the families of other two groups. The results of this study were consistent with Oestman et al. (2001), Eaton et al. (2011) and Nahara et al. (2005) regarding the use of emotional-oriented coping strategies. They said that taking care of a psychiatric patient was a stressful experience. Carers used a range of coping strategies to address their mental health problems. About one-third of families are concerned about suicide attempts and tend to use emotional-oriented coping styles; in such cases they may be adapted to the emotional-based coping style ${ }^{(6,36,37)}$. Folkman and Lazarus argue that if people 
find stressors to be controllable, they will use more focused coping with the problem and otherwise they will orientate to the emotional coping. The problemfocused coping is often used for stressors related to the work and social performances and the emotion-focused coping is used in the case of stressors in the health and personal mood (anxiety and depression) ${ }^{(32)}$.

In this research, the family of non-psychiatric patients used the escape and avoidance coping strategy in comparison with the family of patients with major depression and bipolarity, which it was consistent with Eaton et al. (2011) and Nahara et al. (2005) ${ }^{(6,36)}$. But in their study, Gerson et al. (2010) came to the conclusion that the family of psychiatric patients uses more the coping strategies of cognitive absent-mindedness, problem acceptance, passive assessment and cognitive rehabilitation ${ }^{(38)}$. One of the reasons for this difference in the results may be the fact that in our study family members are tired of the family's psychological condition, the amount of suffering and conflicts of family members, and the pressure of the stigma of the mental patient and turned to an escape and avoidance approach ${ }^{(39)}$. In most psychiatric studies, the patients affected from psychiatric signs were more likely to use an escape and avoidance strategy; based on a systemic viewpoint, the family played a crucial role in the disease, and may as a whole be influenced by the disease and their coping style ${ }^{(14,39,40)}$.

The results of this research also showed that there was no significant difference among the three groups of families regarding the use of problem-oriented coping strategies. The result suggests that all three groups use problem-oriented coping strategies alike. Since the three groups at the level of education were almost identical and most of them had high education, they used these strategies in the same way. These results were consistent with the study done by Barati et al. (2008) ${ }^{(25)}$. Also, the results showed that there was not a significant relationship between quality of life and problemoriented and emotion-oriented coping strategies in the family of patients with major depression disorder and bipolar disorder. There was a significant direct relationship between quality of life and problemoriented coping strategy in the non-patient group. The results of our study were consistent with the study of Aghdasi et al. (2011). Aqdasi noted that the problembased coping strategies directly predict the quality of life and emotion-oriented coping strategies do not explain significantly the quality of life ${ }^{(41)}$.

The results of this study were consistent with the study of Momeni et al. (2012) regarding the significant and positive relationship between problem-oriented coping strategies and quality of life, but in their study, contrary to the present study, there was a negative correlation between emotional coping strategies and quality of life (23). Aghdasi et al. (2011) argue that emotion-oriented coping strategies indirectly correlate negatively with quality of life through negative cognitive regulation styles ${ }^{(41)}$

\section{Conclusion}

The results of this study indicated a significant difference between the families with mental patient and the families without mental patient in terms of overall quality of life and mental health component. This difference was particularly noticeable in families with major depression disorder, so that, regarding the mentioned variables, they were significantly less inferior to those without mental patient. These results suggest that the presence of a mentally patient, especially depressed patients in the family, can greatly affect the quality of life in that family. The present study revealed a significant difference between the three groups in terms of escape and avoidance, as well as emotionaloriented coping strategies, so that the two families of patients with major depression disorder and bipolar disorder did not differ, but the families of individuals without mental disease used less than families of two other groups this strategy. Due to suffering, conflicts and pressures resulting from the presence of psychiatric patients, the families of patients with mental disease were using escape and avoidance strategies, which are considered as negative strategies, more than the family without mental disease. According to the results of this study, if one of the family members has a psychological problem, depending on its type, the quality of life of other family members, especially parents, are exposed to major disorders. There may also be used ineffective strategies in such a family to cope this challenge.

Therefore, considering the results of this study, attention should be paid to health care services, planning, appropriate psychosocial and social measures and coping skills training. It is also recommended to use a stress management method and training program and individual and group psychotherapy sessions to teach skills of coping with stress and stigma. Families need to be educated to raise their awareness about the disease and the process of their patient's treatment.

Since coping strategies are skills that are learned and relatively changeable, and with regard to the role of television and radio in the field of general education, it is recommended that the television and radio allocate few hours for training coping skills in dealing with stress and its management. To this end, the ability to use effective coping strategies increases and affects the quality of life of the society.

This study is a graduate student dissertation in Bushehr University of Medical Sciences.

\section{References}

1. IsHak WW, Balayan K, Bresee C, Greenberg JM, Fakhry H, Christensen S, et al. A descriptive analysis of quality of life using patient-reported measures in major depressive disorder in a naturalistic outpatient setting. Quality of Life Research. 2013;22(3):585-96.

2. Khedri B, Dabaghi P. Study of relationship between coping styles and mental health of soldiers. 2. 2015;2(5):195-200.

3. Sharif Ghaziani Z, Ebadollahi Chanzanegh H, Fallahi Kheshtmasjedi M, Baghaie M. Quality of Life and Its Associated Factors among Mental PatientsFamilies. Journal of Health And Care. 2015;17(2):166-77.

4. Tamizi Z, Ranjbar F, Yaghmaee F, Alavimajd H, Fallahi Khoshknab M. Assessment of Relationship 
between Quality of Life and Coping Strategies in Schizophrenic Patients in Refer To Psychiatric Clinics of Educational Hospitals of Tehran. Quarterly Journal of Rehabilitation. 2013;13(4):12431.

5. Narasipuram S, Kasimahanti S. Quality of life and perception of burden among caregivers of persons with mental illness. life. 2012;21:23.

6. Eaton PM, Davis BL, Hammond PV, Condon EH, McGee ZT. Coping strategies of family members of hospitalized psychiatric patients. Nursing research and practice. 2011.

7. Hashemian P, Edris Sedaghati M. Comparison of family functioning between patients with schizophrenia and patients with Bipolar I disorder. Journal of North Khorasan University of Medical sciences. 2015;7(4):929-37.

8. Farrokhi H, Guilani B, Zamani R, Haddadi kohsar AA. Relation of Coping Style and Attributional Style with Depression. Psychological Research. 2006;9(1,2):11-26.

9. Ghaderi D, Maroufi M, Ebrahimi A. Effect of Cognitive Behavioral Therapy on Reducing Symptoms and Modifying Dysfunctional Attitudes in Patients with Type I and II Bipolar Disorder. J Isfahan Med Sch 2016; 33(358): 1936-42.

10. Hamednia S, Anusheh MR, Khalilzadeh R, Garaghaji R. Efficacy of olanzapine compared to lithium carbonate in treatment of acute manic episode adouble blind study. The Journal of Urmia University of Medical Sciences. 2015;25(11).

11. Sadock BJ, Kaplan \& Sadock's synopsis of psychiatry: behavioral sciences, 11th.Translation Rezai f.Tehran: Arjmand Press; 2015.

12. Lashani A, Bahrami F, Eydi Baygi M, Tork M. Investigation and comparison meta-cognitive therapy (MCT) and psycho - educational family therapy on social performance in bipolar patients. $J$ Res Behave Sci 2015; 13(2): 208-214.

13. Levine IS, Ligenza LR. In their own voices: Families in crisis: A focus group study of families of persons with serious mental illness. Journal of Psychiatric Practice ${ }^{\circledR}$. 2002;8(6):344-53.

14. Omranifard V, Yari A, Kheirabadi GR, Rafizadeh M, Maracy MR, Sadri S. Effect of needs-assessment -based psychoeducation for families of patients with schizophrenia on quality of life of patients and their families: A controlled study. Journal of education and health promotion. 2014;3.

15. Mami Sh, Kykhavny S, Amyryan K, E N. The Effectiveness of Family Psychoeducation (Atkinson and Coia Model) on Mental Health Family Members of Patients with Psychosis. journal of ilam university of medical sciences. 2016;24(1):8-17.

16. ZamZam R, Midin M, Hooi LS, Eng JY, Ahmad $\mathrm{SN}$, Azman SF, et al. Schizophrenia in Malaysian families: A study on factors associated with quality of life of primary family caregivers. International journal of mental health systems. 2011;5(1):1.

17. Li J, Lambert CE, Lambert VA. Predictors of family caregivers' burden and quality of life when providing care for a family member with schizophrenia in the People's Republic of China. Nursing \& health sciences. 2007;9(3):192-8.

18. Bayanzadeh A, Ghasem Abadi R, Karbalaei Nouri A. Surveying the Condition of Chronic Schizophrenic Patients and Their Carers after Discharge. Razi Journal of Medical Sciences. 2003;9 (31):491-500.

19. Boyer L, Caqueo-Urízar A, Richieri R, Lancon C, Gutiérrez-Maldonado J, Auquier P. Quality of life among caregivers of patients with schizophrenia: a cross-cultural comparison of Chilean and French families. BMC family practice. 2012;13(1):1.

20. Magliano L, Fadden G, Madianos M, de Almeida JC, Held T, Guarneri M, et al. Burden on the families of patients with schizophrenia: results of the BIOMED I study. Social psychiatry and psychiatric epidemiology. 1998;33(9):405-12.

21. Wong DFK, Lam AYK, Chan SK, Chan SF. Quality of life of caregivers with relatives suffering from mental illness in Hong Kong: roles of caregiver characteristics, caregiving burdens, and satisfaction with psychiatric services. Health and quality of life outcomes. 2012;10(1):1.

22. Timareh M, Rhimi M, Abbasi P, Rezaei M, Hyaidarpoor S. Quality of life in diabetic patients referred to the Diabete research Center in Kermanshah. Journal of Kermanshah University of Medical Sciences (J Kermanshah Univ Med Sci). 2012;16(1).

23. Momeni Kh,Shabazirad A. pirituality, resiliency and coping strategies with quality of life for students. Journal of Behavioral Sciences.2012sum; 6(2):97103.

24. Jafari F, Moien L, Soroush M R, Mosavi B. quality of life in chemical warfare victims with ophthalmic damage's spouses. Iran J War Public Health. 2011; 3 (3) :8-12.

25. Bayrami M, Nemati Sogolitappeh F. A Comparison of Personality Dimensions, Type $\mathrm{C}$ and Coping Strategies in Cancer Patients and Normal Groups. Journal of Psychology University of Tabriz. 2009;3 (12):17-39.

26. Vahedian M, Hosseinikhah N. Study the relationship between creativity and copying strategies in university students. Journal of Innovation and Creativity in Human Science. 2013 (7).

27. Mazlum befruee N, Afkhami Ardakani M, Shams esfand abadi $\mathrm{H}$, Jalali M. Investigating the Simple and Multiple Resilience and Hardiness with Problem -Oriented and Emotional-Oriented Coping Styles in Diabetes Type 2 in Yazd City. Journal of Diabetes Nursing, Faculty of Nursing and Midwifery Zabol. 2014;1(2):39-49.

28. Friedrich RM, Lively S, Rubenstein LM. Siblings' coping strategies and mental health services: a national study of siblings of persons with schizophrenia. Psychiatric Services. 2008;59(3):2617.

29. Gutiérrez-Maldonado J, Caqueo-Urízar A, Kavanagh DJ. Burden of care and general health in families of patients with schizophrenia. Social 
Psychiatry and Psychiatric Epidemiology. 2005;40 (11):899-904.

30. Foruzandeh N, Delaram M, Noorian C, Deris F. Family functioning in the families of psychiatric patients with difference diagnosis of Hajar hospital Journal of Research in Behavioural Sciences. 2013;11(6).

31. Nasimikhah M, Mirzaian B, Ibrahimi Alavikolayee S. Comparison of Quality of Life and Mental Health in Spouses of the Patients' with Schizophrenia, Bipolar Disorder, Major Depression and Normal Population. Journal of Psychology. 2014;9(3): [Persian].

32. Ghazanfari F, Kadampoor A. The relationship between mental health and coping strategies in citizenship of Khoramabad city. The Quarterly Journal of Fundamentals of Mental Health 2008;10 (37):47-54.

33. Montazeri A, Goshtasebi A, Vahdaninia M, Gandek B. The Short Form Health Survey (SF-36): translation and validation study of the Iranian version. Quality of life research. 2005;14(3):875-82.

34. Ghadamgahi J, Dejkam M, Behrozyan A, Feiz A. Quality of social relationships, stress and coping strategies in patient with coronary heart. Journal of Andisheh-va-Raftar. 1998;4(1):1-12.

35. Rostami AM, Ahadi H, Cheraghaligol H. The Prediction of Coping Strategies Based on Personality Traits in Irritants Affiliates. Quarterly Journal of Research on Addiction. 2013;26(7):11126.
36. Nehra R, Chakrabarti S, Kulhara P, Sharma R. Caregiver-coping in bipolar disorder and schizophrenia. Social Psychiatry and Psychiatric Epidemiology. 2005;40(4):329-36.

37. Östman M, Hansson L. The relationship between coping strategies and family burden among relatives of admitted psychiatric patients. Scandinavian Journal of Caring Sciences. 2001;15(2):159-64.

38. Gerson R, Wong C, Davidson L, Malaspina D, McGlashan T, Corcoran C. Self-reported coping strategies in families of patients in early stages of psychotic disorder: an exploratory study. Early intervention in psychiatry. 2011;5(1):76-80.

39. Torabi Z, Eghlima M, Khanke H R, Reza Soltani P. Examine between Family Burden and Family Function (Family with Chronic Neurosis Children). Social Welfare. 2014; 13 (51) :133-149.

40. Ranjbar F, Tamizi Z, Yaghmai F, Alavi H, Majd, Falahi $M$, et al. Coping strategies of schizophrenic patients referring to psychiatry clinics at hospitals affiliated to universities of medical sciences in Tehran. Journal of Nursing and Midwifery. 2008;17 (59):5-11.

41. Naghi aghdasI A, Eydi R. A study of the relationship between mental health and confronting procedures among the spinal cord. Journal of instruction and evaluation) journal of educational sciences. 2012;4 (16):51-67. 